\title{
Kajian Potensi Erosi Di Daerah Aliran Sungai Babon Menggunakan Permodelan GeoWEPP
}

\author{
Dimas Jalu Setyawan ${ }^{1}$, Revangga Dhanda Pratama ${ }^{1}$, Budi Santosa ${ }^{2}$ \\ email: dimasjalu04@gmail.com ${ }^{1}$ \\ revanggadandha@gmail.com
}

\author{
Program Studi Teknik Sipil, Fakultas Teknik, Universitas Katolik Soegijapranata \\ Jl. Pawiyatan Luhur IV/1, Bendan Dhuwur, Semarang 50234
}

\begin{abstract}
Abstrak
Pada waktu intensitas curah hujan yang tinggi di daerah semarang, air yang terdapat dalam sungai Babon sempat meluap, sehingga meyebabkan tergenangnya sebagian wilayah yang berdekatan dengan aliran sungai Babon. Hal ini memiliki banyak faktor yang salah satunya yaitu erosi dan sedimen yang dihasilkan. Penelitian ini bertujuan untuk mengkaji pontensi erosi di daerah aliran sungai Babon, dengan menggunakan permodelan Geospatial Interface for Water Erosion Prediction Project (GeoWEPP). Hasil dari permodelan tersebut yaitu besarnya laju erosi dan persebaran erosi di daerah penelitian. Periode prediksi erosi pada penelitian ini yaitu pada tahun 2006 - 2015. Data yang dibutuhkan dalam pengoprasian GeoWEPP yaitu Digital Elevation Model, data iklim, data penggunaan lahan, dan data jenis tanah. Berdasarkan dari proses GeoWEPP pada daerah aliran sungai Babon menghasilkan laju erosi sebesar 36,1 ton/ha/th dan hasil sedimen sebesar 26075,2 ton/th. Dari hasil laju erosi yang dihasilkan dibagi dengan laju erosi wajar mendapatkan indeks Tingkat Bahaya Erosi (TBE) sebesar 3,6 atau termasuk TBE sedang. Berdasarkan peta persebaran erosi yang dihasilkan, daerah yang mengalami laju erosi terbesar pada daerah Ungaran. Hal tersebut dikarenakan termasuk daerah dataran tinggi dan memiliki nilai kelerangan tinggi.
\end{abstract}

Kata kunci: Erosi, Daerah Aliran Sungai, GeoWEPP

\begin{abstract}
At the time of the high intensity of rainfall in Semarang, the water contained in the Babon River had overflowed, resulting in flooding of parts of the area adjacent to the Babon river flow. This matter has many factors, there are erosion and sediment produced. This study aims to study erosion potential in the Babon watershed, using the Geospatial Interface for Water Erosion Prediction Project (GeoWEPP) modeling. The results of the modeling are the amount of erosion rate and erosion distribution in the study area. The erosion prediction period in this study is in 2006 - 2015. Data needed in GeoWEPP operation are Digital Elevation Model, climate data, land use data, and soil type data. Based on the GeoWEPP process in the Babon watershed the erosion rate was 36.1 tons / ha / year and the sediment yield was 26075.2 tons / year. From the results of the erosion rate produced divided by the reasonable erosion rate get the Erosion Hazard Level index (TBE) of 3.6 or including medium TBE. Based on the distribution of erosion maps produced, the area experienced the greatest erosion rate in the Ungaran region. This is due to the fact that it belongs to the highlands and has a high slope value.
\end{abstract}

Keywords: Erosion, Watershed, GeoWEPP 


\section{PENDAHULUAN}

\subsection{Latar Belakang}

Erosi merupakan salah satu penyebab terjadinya banjir di sungai sungai yang ada di seluruh wilayah di dunia, ini menjadi permasalahan yang banyak ditemui. Erosi pada mulanya adalah sebuah proses yang alami, akan tetapi di jaman sekarang ini dengan aktivitas manusia yang semakin padat dapat mempercepat proses terjadinya erosi. Menurut FAO dalam (Bagus, 2015) faktor utama yang menyebabkan mempercepatnya terjadi erosi adalah penggembalaan berat (35\%), penggundulan hutan $(30 \%)$, dan pertanian (28\%). Salah satu permasalahan yang ditimbulkan dari erosi yaitu sedimentasi yang menyebabkan penyempitan dan pendangkalan Daerah Aliran Sungai (DAS), hal ini dapat berdampak terjadinya banjir.

Pada setiap wilayah DAS pasti mengalami erosi, namun dalam besarnya laju yang berbeda - beda sehingga menghasilkan sedimen yang jumlahnya berbeda juga. Salah satu wilayah DAS yang terindikasi memiliki erosi dalam jumlah besar yaitu DAS Babon yang berada di lereng utara gunung Ungaran dan terbagi oleh 3 Sub DAS yaitu DAS Pengkol, DAS Gung, DAS Babon Hilir. Wilayah di sekitar DAS Babon digunakan untuk pemukiman dan lahan kering. Wilayah DAS Babon memiliki beberapa stasiun hujan yaitu Banyumeneng, Simongan, Kalisari, Karangroto, dan Pucang Gading (BBWS, 2017). Pada saat curah hujan tinggi (Tabel 1.2), air di sungai Babon pernah meluap karena tidak dapat menampung debit air yang cukup besar berakibat jalur Pantura Demak Semarang terendam banjir setinggi $40-50$ $\mathrm{cm}$, dengan air yang bercampur dengan
Dengan menggunakan model GeoWEPP dapat menghasilkan pendugaan erosi, sehingga dapat diketahui besaran laju erosi yang terjadi di DAS Babon.

\subsection{Rumusan Masalah}

Penggunaan lahan yang tidak sesuai seperti menggunakan bantaran sungai sebagai pemukiman di daerah wilayah DAS Babon berdampak terjadinya erosi dan sedimatasi. Laju erosi yang besar menghasilkan sedimen yang masuk kedalam aliran sungai, sehingga menjadikan penyempitan dan pendangkalan sungai sehingga berakibat terjadinya banjir.

\subsection{Tujuan Penelitian}

Beberapa tujuan dari penelitian ini yaitu:

1. Mengetahui besaran potensi laju erosi yang terjadi di DAS Babon,

2. Mengetahui potensi hasil sedimen dengan mengaplikasikan model GeoWEPP.

\section{TINJAUAN PUSTAKA}

\subsection{Curah Hujan}

Curah hujan merupakan air hujan yang turun pada suatu daerah dan waktu tertentu dengan jumlah yang berbeda-beda pada setiap tempatnya (Darmawan, Hani'ah, \& Suprayogi, 2017).

Tabel 1. Klasifikasi Curah Hujan

\begin{tabular}{|c|l|c|c|}
\hline No & Deskripsi & $\begin{array}{c}\text { Rata-rata } \\
\text { Curah Hujan } \\
\text { (mm/hari) }\end{array}$ & Nilai \\
\hline 1 & Sangat lebat & $>100$ & 5 \\
\hline 2 & Lebat & $51-100$ & 4 \\
\hline 3 & Sedang & $21-50$ & 3 \\
\hline 4 & Ringan & $5-20$ & 2 \\
\hline 5 & $\begin{array}{l}\text { Sangat } \\
\text { ringan }\end{array}$ & $<5$ & 1 \\
\hline
\end{tabular}

Sumber: Theml, S. 2008 : Katalog

Methodologi Penyusunan Peta Geo Hazard dengan GIS 


\subsection{Daerah Aliran Sungai}

Daerah aliran sungai (DAS) adalah suatu daerah yang dibatasi dengan gunung, punggung-punggung bukit,atau tanggul dan merupakan satu kesatuan yang terdapat sungai dan anak-anak sungai yang berfungsi untuk menampung, menyimpan dan mengalirkan air yang berasal dari curah hujan ke danau atau laut secara alami.

\subsection{Erosi}

Pengertian erosi merupakan sebuah proses terlepasnya butiran tanah dari kumpulan tanah yang padat di suatu wilayah dan material tersebut terbawa oleh aliran air atau angin kemudian mengalami pengendapan ditempat yang lain menurut Suripin, 2002 dalam (Sutapa, 2010). antara lain:

Jenis Erosi menurut bentuknya

a. Erosi Permukaan (Sheet Erosion)

b. Erosi Alur (Rill Erosion)

c. Erosi Parit (Gully Erosion)

d. Erosi Percikan (Splash Erosion)

e. Erosi Tebing Sungai (Stream Bank Erosion)

Erosi terjadi dengan 3 tahapan, yaitu lepasnya partikel tunggal tanah dari massa tanah. Kemudian pada tahap kedua merupakan pengangkutan partikel yang lepas oleh media yang erosive seperti air. Tahap ketiga partikel yang terbawa oleh media pengangkut mengalami pengendapan.

US D-48 merupakan alat yang dikembangkan oleh Federal Inter Agency Sedimentation Project (FIASP) untuk mengukur debit sedimen melayang. Alat ini dirancang sedemikian rupa agar dapat menangkap aliran air yang bercampur dengan sedimen pada posisi tegak lurus aliran dan kecepatan aliran yang masuk ke nosel akan mempunyai nilai harga yang mendekati dengan kecepatan aliran disekitarnya.

Dampak erosi dapat mempengaruhi lingkungan jika laju erosi di suatu tempat sangat besar.

\subsection{Sedimentasi}

Sedimentasi merupakan proses pengendapan material tanah setelah mengalami proses pengakutan dan erosi.

\section{METODE PENELITIAN}

\subsection{Lokasi Penelitian}

Penentuan lokasi penelitian dimaksudkan untuk mengetahui gambaran umum daerah penelitian yang akan dijadikan studi kasus, lokasi yang menjadi studi kasus penelitian adalah Sungai Babon di Kecamatan Tembalang Kota Semarang Provinsi Jawa Tengah terlihat pada Gambar 1.

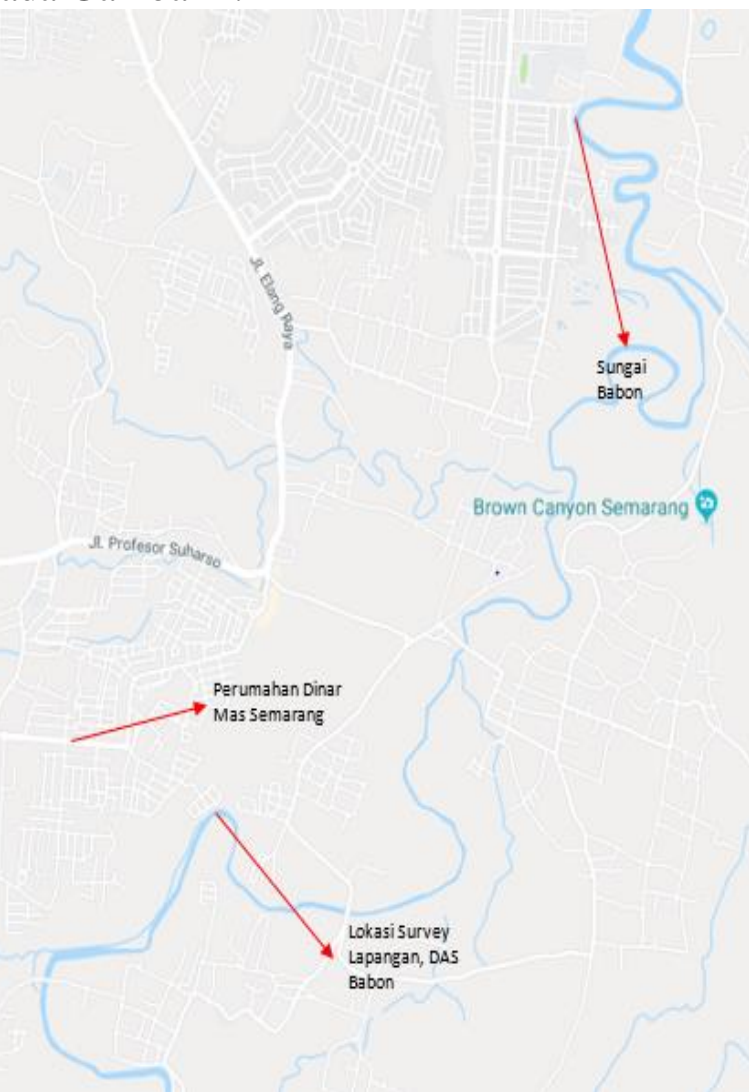

Gambar 1. Lokasi Penelitian DAS Babon 


\subsection{Parameter Penelitian}

Kajian pada penelitian ini menggunakan software GeoWEPP, WEPPwin, dan ArcGIS.

\subsection{Tahapan Penelitian}

Tahapan penelitian yang digunakan yang pertama yaitu melakukan studi literatur, pengumpulan data, pengolahan data, analisis data.

\subsection{Diagram Alir Penelitian}

Diagram alir secara umum merupakan penjelasan dan tahapan proses penelitian yang dilakukan dari awal penelitian dimulai hingga penelitian selesai. Diagram alir secara umum dapat dijelaskan melalui bagan alir Gambar 2.

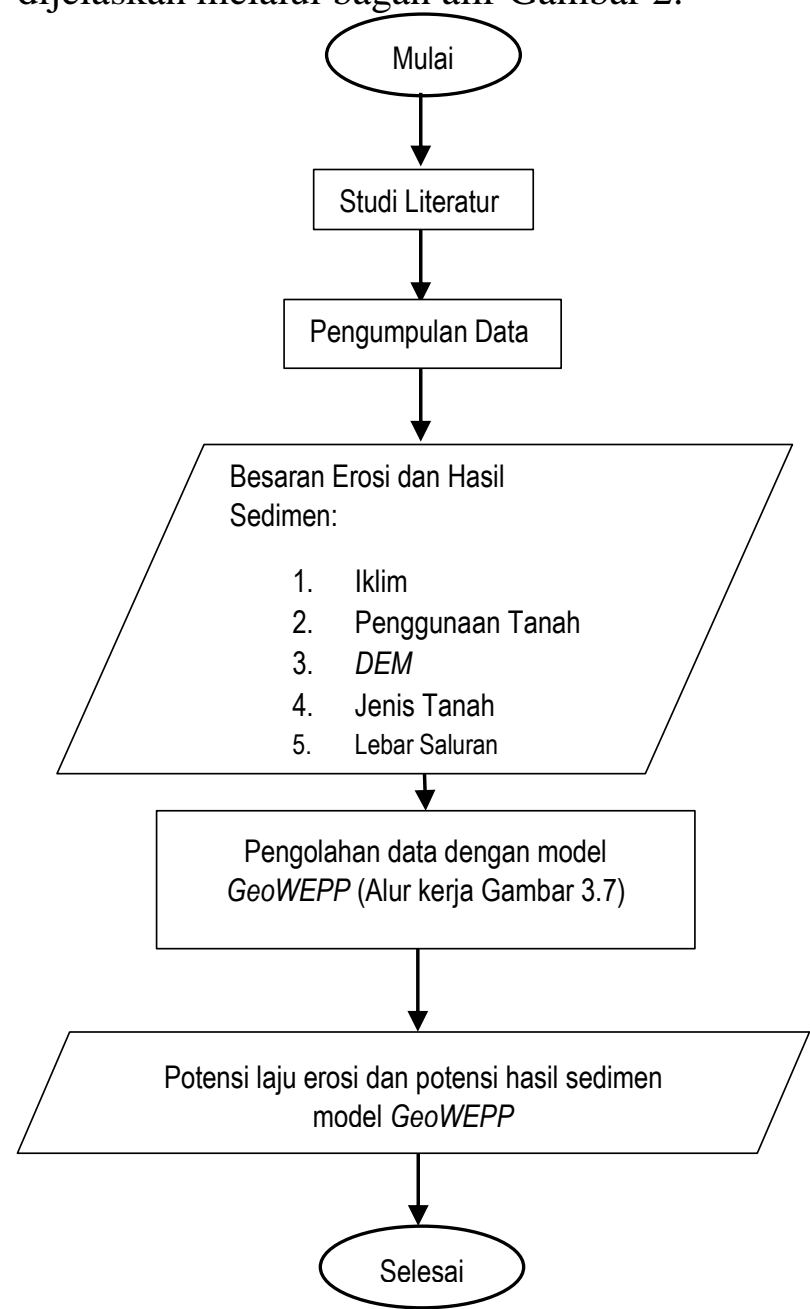

Gambar 2. Diagram Alir Penelitian

\section{GAMBARAN UMUM DAERAH PENELITIAN}

\subsection{Letak Geografis Daerah Penelitian}

Batasan - batasan dari DAS Babon adalah sebagai berikut (Gambar 3).

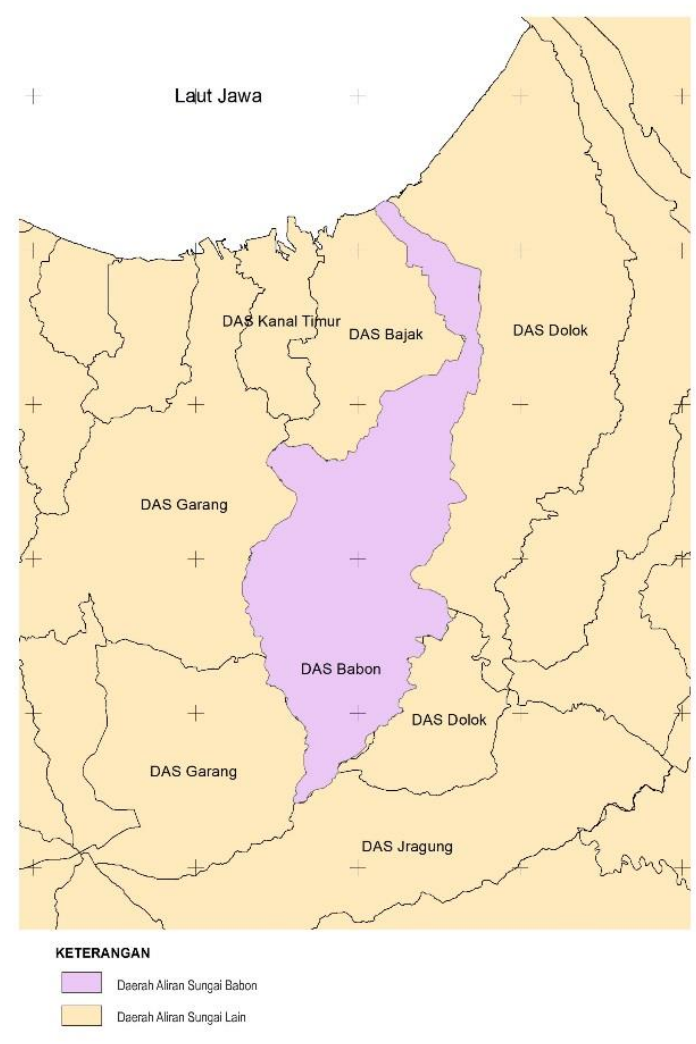

Gambar 3. Peta Batas DAS Babon

\subsection{Iklim}

Berdasarkan analisis data iklim menunjukkan bahwa wilayah DAS Babon mempunyai suhu udara rata-rata $27.5^{\circ} \mathrm{C}$, dengan temperatur udara pada bulan terdingin sebesar $21.5^{\circ} \mathrm{C}$ dan temperatur udara pada bulan terpanas sebesar $35.0^{\circ} \mathrm{C}$, sedang curah hujan ratarata tahunan selama 10 tahun terakhir adalah $2210 \mathrm{~mm}$.

\subsection{Topografi}

Klasifikasi lereng dibagi menjadi 6 kelas yaitu kelas $1=0-2 \%$, kelas $2=0-8 \%$, kelas $3=8-15 \%$, kelas $4=15-25 \%$, kelas 
$5=25-40 \%$, dan kelas $6=>40 \%$ menurut Sandy 1998 dalam (Nugroho S., 2012).

Babon terletak pada ketinggian antara 2 meter di atas permukaan laut di bagian Utara (hilir) hingga sekitar 200 meter di bagian hulu, terlihat pada Gambar 4.

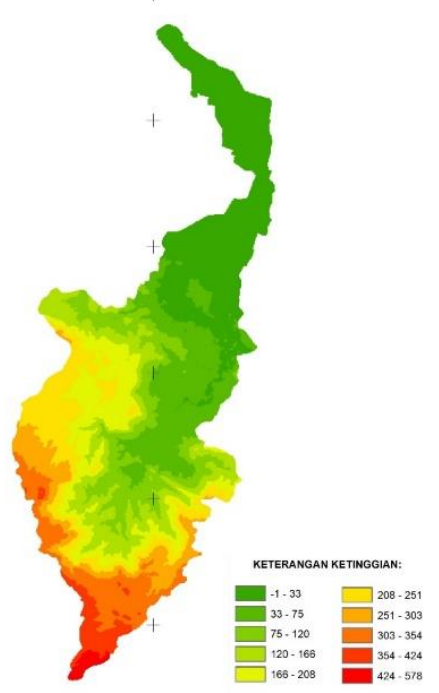

Gambar 4. Peta Ketinggian DAS Babon

\subsection{Penggunaan Lahan dan Jenis Tanah}

Tataguna lahan pada DAS Babon dapat dilihat seperti pada Gambar 5.

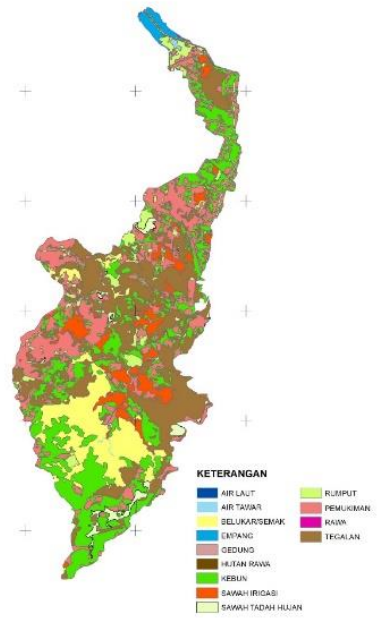

Gambar 5. Peta Tata Guna Lahan DAS Babon
Peta jenis tanah yang ada di DAS Babon dapat dilihat dalam Gambar 6. dan karakteristik tanah dapat dilihat dalam Tabel 2.

Tabel 2. Karakteristik Tanah DAS Babon

\begin{tabular}{|c|c|c|}
\hline No & Jenis Tanah & Karakteristik \\
\hline 1 & Aluvial & $\begin{array}{lr}\text { Tanah endapan } \\
\text { terbentuk dari } \\
\text { lumpur dan pasir } \\
\text { halus. Bertekstur } \\
\text { liat. }\end{array}$ \\
\hline 2 & $\begin{array}{l}\text { Asosiasi } \\
\text { Aluvial } \\
\text { Kelabu }\end{array}$ & Liat dan pasir \\
\hline 3 & Regosol & $\begin{array}{l}\text { Tanah yang } \\
\text { mengandung abu } \\
\text { dan pasir vulkanik, } \\
\text { mempunyai tekstur } \\
\text { tanah yang kasar, } \\
\text { butiran- butiran } \\
\text { kasar, dan } \\
\text { mempunyai sifat } \\
\text { peka terhadap erosi } \\
\text { tanah. }\end{array}$ \\
\hline 4 & Grumosol & $\begin{array}{lr}\text { Terbentuk } & \text { dari } \\
\text { batuan } & \text { induk } \\
\text { kapur, } & \text { tuffa } \\
\text { vulkanik, abu pasir } & \text { dan } \\
\text { dantermediate. } & \\
\text { interm } & \\
\text { Bertekstur } & \\
\text { lempung. } & \end{array}$ \\
\hline 5 & $\begin{array}{l}\text { Latosol } \\
\text { Coklat } \\
\text { Kemerahan }\end{array}$ & $\begin{array}{ll}\text { Tanahnya } & \\
\text { berwarna } & \text { merah, } \\
\text { coklat, } & \text { hingga } \\
\text { kekuning- } & \\
\text { kuningan. } & \text { Tekstur } \\
\text { tanahnya adalah } \\
\text { liat. }\end{array}$ \\
\hline No & Jenis Tanah & Karakteristik \\
\hline 6 & $\begin{array}{l}\text { Mediteran } \\
\text { Coklat Tua }\end{array}$ & $\begin{array}{l}\text { Hasil pelapukan } \\
\text { batuan kapur keras }\end{array}$ \\
\hline
\end{tabular}




\begin{tabular}{|l|l|lr|}
\hline & $\begin{array}{lr}\text { dan } & \text { batuan } \\
\text { sedimen. } & \text { Warna } \\
\text { tanah ini } & \text { berkisar } \\
\text { antara } & \text { merah } \\
\text { sampai kecoklatan. }\end{array}$ \\
\hline
\end{tabular}

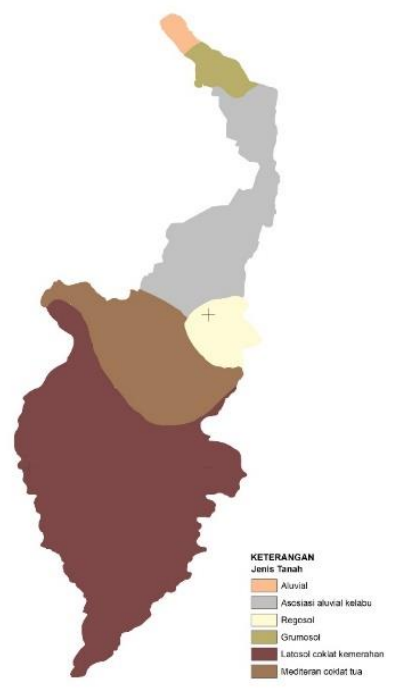

Gambar 6. Peta Jenis Tanah DAS Babon

\section{HASIL DAN PEMBAHASAN}

\subsection{Pengolahan Kondisi Iklim}

Iklim pada DAS Babon di olah dengan menggunkan metode Cligen yang telah dilakukan sesuai dengan yang di jelaskankan pada metodologi penelitian, tentang pengolahan data iklim.

Data tersebut menggunakan data periode 2006 - 2015, dengan suhu maksimum tertinggi terjadi pada bulan Agustus yaitu $33,04^{\circ} \mathrm{C}$ dan terendah juga pada bulan Agustus yaitu $23,82^{\circ} \mathrm{C}$. (Gambar 7.)

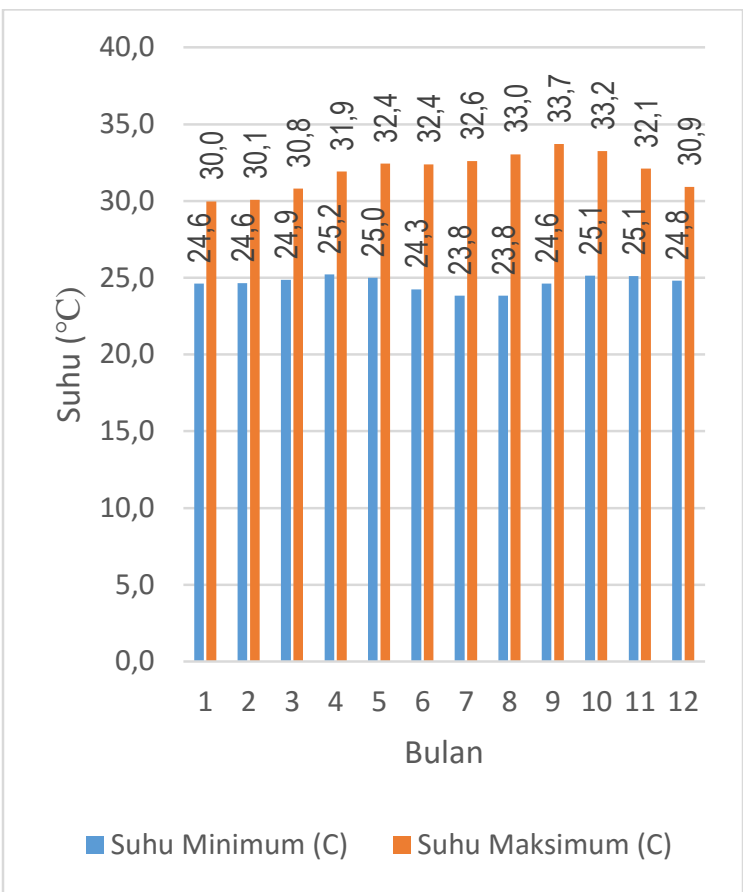

Gambar 7. Grafik Suhu Rerata Bulanan Periode 2006-2015

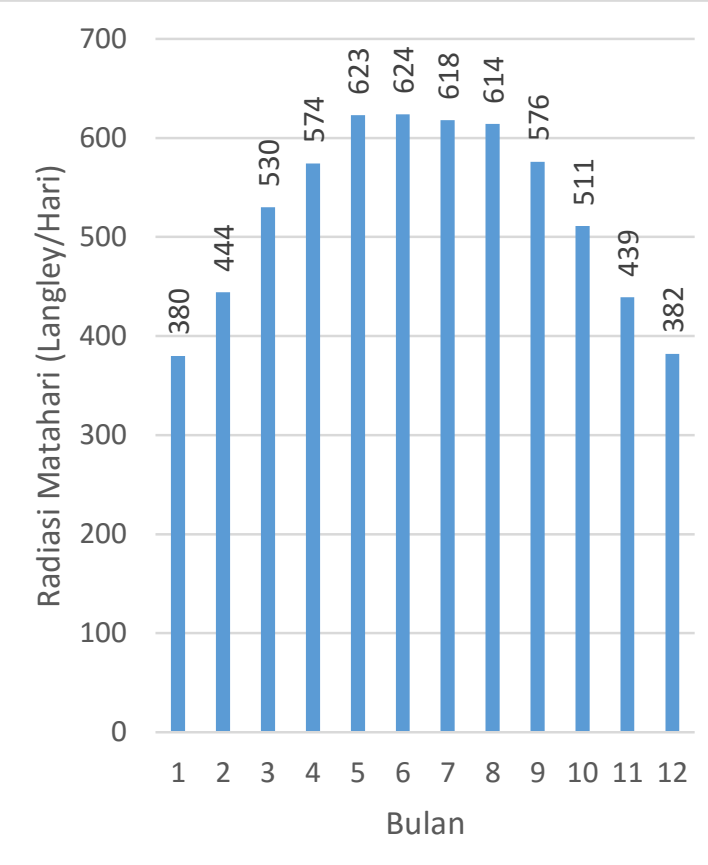

Gambar 8. Grafik Radiasi Matahari Periode 2006-2015 


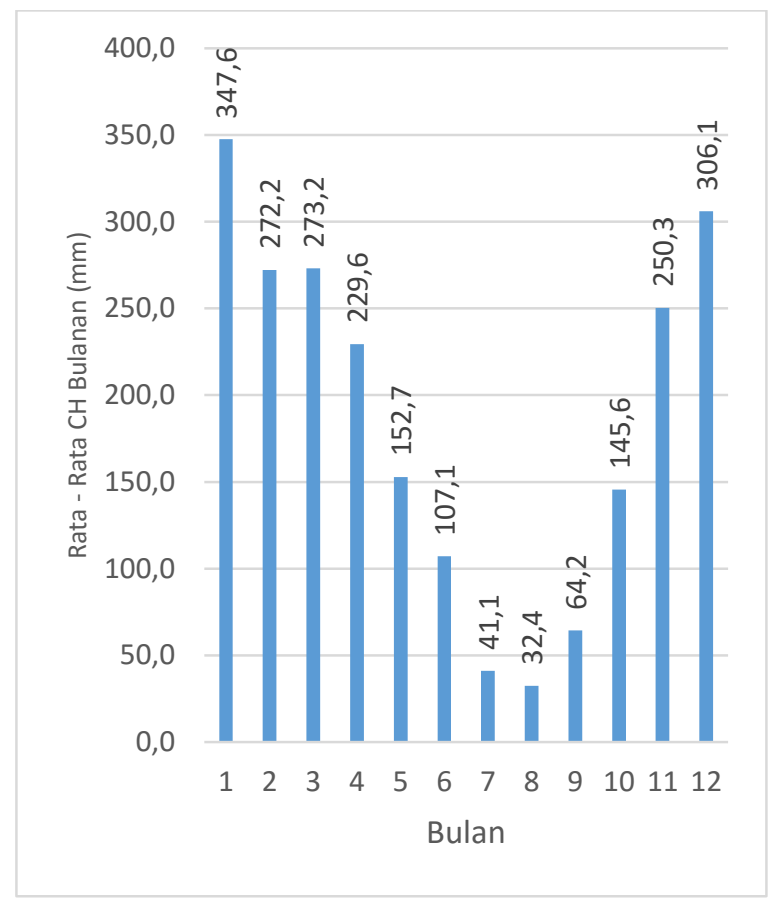

\section{Gambar 9. Grafik Rata-rata CH} Bulanan Periode 2006-2015

Pada grafik curah hujan rata - rata bulanan yang dihasilkan Cligen, terdapat dua puncak curah hujan yaitu pada bulan Januari dan bulan Desember atau memiliki tipe iklim ekuatorial. (Gambar 9.)

\subsection{Pendugaan Erosi dan Sedimen dengan Model GeoWEPP}

Dengan terbatasnya luasan dearah yang dapat di simulasikkan oleh GeoWEPP, maka dalam penelitian ini DAS Babon diambil dari hulu hingga titik kontrol yang berada di bendung Pucang Gading. (Gambar 10.)

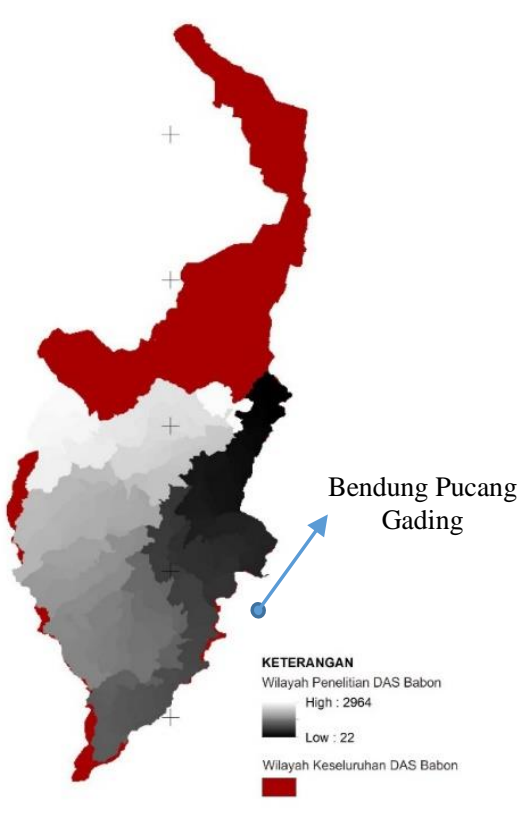

\section{Gambar 10. Peta Wilayah Penelitian DAS Babon}

\subsection{Tingkat Bahaya Erosi}

DAS Babon meliki indeks TBE sebesar 3,6 termasuk kriteria TBE sedang dilihat dari tabel 2.3 kriteria bahaya erosi.

\subsection{Laju Erosi dan Hasil Sedimen}

Dari hasil permodelan dengan menggukan GeoWEPP besaran erosi di daerah DAS Babon yaitu sebesar 36,1 ton/ha/tahun dapat dilihat pada Lampiran A dan detail dari hasil permodelan dapat dilihat pada Lampiran B.

Besaran hasil sedimen di daerah DAS Babon yaitu sebesar 260756,2 ton/tahun.

Dari Gambar 11 dapat dilihat bahwa kontribusi sedimen terbesar yakni dengan dengan nilai sediment yield $>4 \mathrm{~T}$ ( $\mathrm{T}=10 \mathrm{ton} / \mathrm{ha} / \mathrm{thn}$ ) berada pada selatan DAS yaitu pada daerah di Ungaran ditandai dengan wilayah yang berwarna merah. 


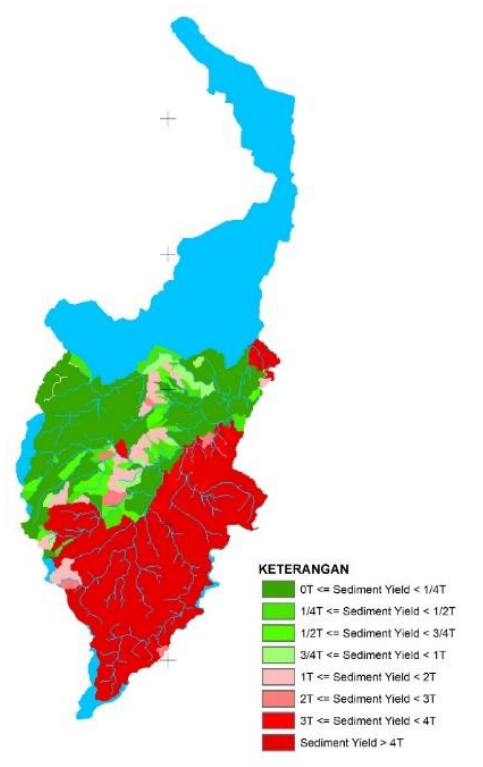

Gambar 11. Peta Off-site DAS Babon

\section{KESIMPULAN DAN SARAN}

\subsection{Kesimpulan}

Kesimpulan yang dapat diambil dari hasil analisis yang sudah dilakukan adalah sebagai berikut:

1. Berdasarkan dari permodelan GeoWEPP pada Daerah Aliran Sungai Babon, besaran erosi dan hasil sedimen berbeda - beda tiap Sub DASnya. Potensi laju erosi seluruh DAS Babon yaitu sebesar 36,1 T/ha/tahun. Hasil permodelan dapat dilihat pada Lampiran A dan B. Program GeoWEPP hanya dapat mensimulasikan erosi dan sedimen untuk luasan area tertentu saja (< 16000 ha).

2. Sedangkan untuk potensi hasil sedimennya yaitu sebesar 260756,2 ton/tahun. Kontribusi sedimen terbesar yaitu > 4T berada pada daerah Ungaran, dikarenakan merupakan wilayah dataran tinggi dengan nilai kelerengan $>40 \%$. Berdasarkan hasil running kriteria tingkat bahaya erosi, DAS Babon berada pada kondisi tingkat bahaya erosi sedang.

\subsection{Saran}

Saran yang dapat diberikan dari hasil analisis yang sudah dilakukan adalah sebagai berikut:

1. Perlunya penataan kota yang tepat, misalkan tidak membangun pemukiman disekitar pinggir sungai Babon apabila belum dilakukan perkerasan tanah pada area pinggir sungai Babon. Hal tersebut diperlukan agar tidak memperbesar laju erosi.

2. Perlunya reboisasi hutan yang gundul di sekitar aliran sungai Babon. Hal ini bertujuan agar air dapat diserap oleh tanaman dan partikel tanah tidak mudah lepas oleh air hujan dan limpasan yang terjadi.

3. Perlunya penelitian lebih lanjut tentang kandungan sedimen, agar sedimen yang dihasilkan dapat digunakan untuk hal yang berguna seperti sebagai urugan, pupuk, dan tanah perkebunan.

4. Dalam penggunaan permodelan GeoWEPP diperlukan data yang diambil dari DAS Babon agar hasil dari proses GeoWEPP dapat digunakan sebagai bahan perencanaan atau kajian berikutnya. Pada tugas akhir ini data tanah yg diambil merupakan data dari jurnal di seluruh Indonesia tidak langsung mengambil data tanah dari wilayah DAS Babon. 


\section{DAFTAR PUSTAKA}

Afifah, F. N. (2010). Pendugaan Kebutuhan Air di DAS BABON. Bogor.

Arfaini, J., \& Handayani, H. H. (2016). Analisa Data Foto Udara untuk DEM dengan Metode TIN, IDW, dan Kriging. Jurnal Teknik ITS.

Asdak, C. (1995). Hidrologi dan Pengelolaan Daerah Aliran Sungai. Yogyakarta.

Bagus, S. A. (2015). Aplikasi Model Geospatial Interface for Water Erosion Prediction (GEOWEPP) Untuk Prediksi Laju Erosi Di DAS Jono, Kecamatan Piyungan, Kabupaten Bantul, Daerah Istimewa Yogyakarta. 2.

BBWS. (2017). Curah Hujan Semarang.

BPS. (2013). BPS. Dipetik Januari 07, 2017, dari BPS.go.id: www.BPS.go.id

Bunganaen, W. (2011). Perubahan Kondisi Tataguna Lahan Terhadap Volume Sedimentasi Pada Embung Bimoku di Lasiana Kota Kupang. 46-47.

Choirul D, K. R. (2015). Pengendalian Banjir DAS Dolok - Penggaron Pada Sungai Babon. Jurnal Karya Teknik Sipil, 242-249. Dipetik Januari 07, 2017, dari BPS.go.id: www.BPS.go.id

Darmawan, K., Hani'ah, \& Suprayogi, A. (2017). Analisis Tingkat Kerawanan Banjir di Kabupaten Sampang Menggunakan Metode Overlay dengan Scoring Berbasis
Sistem Informasi Geografis. 3334.

Erisman. (2017). Kota Semarang Dalam Angka. Semarang: BPS Kota Semarang.

Humberto Blanco, R. L. (2008). Principles of Soil Conservation and Management. Kansas: Springer.

Liputan 6. (2014, Febuari 5). Diambil kembali dari https://www.liputan6.com/news/re ad/818323/sungai-babon-disemarang-meluap-jalur-panturalumpuh

Minkowski, M., \& Renschler, C. (2008). GeoWEEP for ArcGis 9.x Full Version Manual. 40-41.

Mulyono, D. (2014). Analisis Karakteristik Curah Hujan di wilayah Kabupaten Garut Selatan. 3.

Nugroho, S. (2012). Pendugaan Laju Erosi dan Hasil Sedimen Model GeoWepp serta Kaitannya dengan Bentuk DAS di Daerah Aliran Ci Lember. DKI Jakarta.

Prabowo, A. (2015, November 13). MNC Group. Diambil kembali dari Koran Sindo Web site: http://koransindo.com/page/news/2015-1013/6/26/Kota_Semarang_Bisa_Jad i_Venice_van_Java

Pratiwia, Y., Muliadi, \& Jumarang, M. I. (2014). Analisis Konsentrasi dan Laju Angkutan Sedimen Melayang pada Sungai Sebalo di Kecamatan Bengkayang. 99. 
Project, Federal Interaagency Sedimentation. (t.thn.). Sampling With The Us Dh-48 DepthIntegrating Suspended-Sediment Sampler.

Rahayu, S., Widodo, R. H., Noordwijk, M. v., Suryadi, I., \& Verbist, B. (2009). Monitoring Air di Daerah Aliran Sungai. Bogor: ICRAF Asia Tenggara.

Rantung, M. M., Binilang, Wuisan, \& Halim. (2013). Analisis Erosi dan Sedimentasi Lahan di Sub DAS Panasen Kabupaten Minahasa. Jurnal Sipil Statik.

Rosytha, A., \& Taufik, M. (2011). Studi Analisa Banjir dengan Menggunakan Teknologi SIG di Kabupaten Bojonegoro.

Setiawan, B. A. (2015). Aplikasi Model Geospatial Interface For Water Erosion Prediction Project(Geowepp) Untuk Prediksi Laju Erosi Di Das Jono, Kecamatan Piyungan, Kabupaten Bantul, Daerah Istimewa Yogyakarta. 2.

Sriyana. (2011). Kajian Karakteristik DAS Tuntang dan Model Pengelolaan DAS Terpadu. Teknik.

Subekti. (2012). Prediksi Erosi Lahan dengan Metode USLE. Jurnal Fondasi.

Sutapa, I. w. (2010). Analisis Potensi Erosi Pada Daerah Aliran Sungai (DAS) DI Sulawesi Tengah. 2.

Utoyo, B. (2009). Geografi Membuka Cakrawala Dunia. Jakarta: Pusat Perbukuan.
Yogafanny, E. (2015). Pengaruh Aktifitas Warga di Sempadan Sungai terhadap Kualitas Air Sungai Winongo. Jurnal Sains dan Teknologi Lingkungan.

Rosytha, A., \& Taufik, M. (2011). Studi Analisa Banjir dengan Menggunakan Teknologi SIG di Kabupaten Bojonegoro.

Setiawan, B. A. (2015). Aplikasi Model Geospatial Interface For Water Erosion Prediction Project(Geowepp) Untuk Prediksi Laju Erosi Di Das Jono, Kecamatan Piyungan, Kabupaten Bantul, Daerah Istimewa Yogyakarta. 2.

Sriyana. (2011). Kajian Karakteristik DAS Tuntang dan Model Pengelolaan DAS Terpadu. Teknik.

Subekti. (2012). Prediksi Erosi Lahan dengan Metode USLE. Jurnal Fondasi.

Sutapa, I. w. (2010). Analisis Potensi Erosi Pada Daerah Aliran Sungai (DAS) DI Sulawesi Tengah. 2.

Utoyo, B. (2009). Geografi Membuka Cakrawala Dunia. Jakarta: Pusat Perbukuan.

Yogafanny, E. (2015). Pengaruh Aktifitas Warga di Sempadan Sungai terhadap Kualitas Air Sungai Winongo. Jurnal Sains dan Teknologi Lingkungan. 